\title{
Study on the Integrated Construction of Agricultural Industry in Wuhan Urban Agglomeration
}

\author{
Zhao Yingnian \\ Huazhong Agricultural University \\ Wuhan, China \\ E-mail: ynzhao@mail.hzau.edu.cn
}

\begin{abstract}
The agricultural industrial integration is one of the most important measures for the development of urban and rural areas in China, and it is a powerful promoter of agricultural modernization. Based on reviewing the relevant research on the integration of agricultural industry, this paper has summed up working experiences and promoting measures of agricultural industrial integration in Wuhan Urban Agglomeration, sorted out the main issues and put forward the corresponding countermeasures in order to promote comprehensive reforms in the field of Agriculture.
\end{abstract}

Keywords-Wuhan Urban Agglomeration; Agricultural Industrial Integration; Two Orientations of Agriculture; Scale Operation; Study

\section{INTRODUCTION}

NO.1 Central Document in 2014 requests to resolutely get rid of the drawbacks of the institutional mechanism, to unswervingly adhere to the basic position of agriculture, and to accelerate agricultural modernization moreover. Agricultural industrialization is the new business model refers to the purpose of agricultural producers to enhance the market competitiveness of products and centralized management of land. Under the socialist market economy, Agricultural industrialization is about to be a new business in the form of agricultural production with a greater optimization, better allocation of resources and agriculture regrouping of production factors on the scope and higher level. In addition, Agricultural industrialization is the traditional agricultural production, and the fundamental reform of management system [1]. Therefore, the road to the integration of agricultural industry is one of the most important measurements for the development of China's urban areas and rural areas; furthermore, it is also a powerful promoter of agricultural modernization. In recent years, many scholars have carried out the research on the integration of agricultural industry. Niu Ruofeng points out, "agriculture, agricultural industry are the integration of production and marketing integration management" abbreviation, namely: "agricultural industrialization", internationally known as "agricultural integration", and gives the "leading unit and multiple participants have a direct common interests", "whether there is a certain organization or carrier connection" and "if there is a system to maintain" the "three" standard [2]; Wang Yafei et al. believe, farmer cooperatives integration organization mode is the most conducive method to improve the degree of organization for farmers, more importantly, it can reduce transaction costs, and it can also enhance the stability of vertical relationship of agricultural industry chain, which leads to the future Chines development direction of the agricultural industry organizations [3]; Han Yanqi et al. propose, the implementation of the "giant plan", the acceleration of the agricultural product processing industry cluster development and technology innovation, all the methods above strengthen brand building and perfecting the management service system, with the purpose to promote the development of agricultural industrialization in Hubei province[4]. In view of this, this paper summarizes the work experience and measures in the implementation of the integration of agricultural industry in Wuhan Urban Agglomeration in Hubei Province, combing the main problems, and puts forward the corresponding countermeasures and suggestions, so as to promote comprehensive reforms in the field of Agriculture.

\section{WORKING EXPERIENCE}

A. With Agricultural Science and Technology as the Support, Explored a Number of "Two" Agricultural New Model

In order to improve agricultural resources with high efficiency, Hubei Province Department of Agriculture promote crops for inter planting cropping patterns actively, and applies several modes including the seed precision semi precision seeding mode, pesticide mist spray pattern, pig farming 150 patterns, pig biogas fruit, fish, vegetables) mode, and mushroom rice mode, crayfish in the field of rice farming model. Application of the modes improves the utilization efficiency of land, seeds, and pesticides. Wuhan city adheres to tripe cropping system of oil rice, vegetables rice. 2012 applied area of $80 \%$ above, multiple cropping index of crop up to $230 \%$, which is higher than the similar ecological county by more than $10 \%$. Rate of output per unit area is more than $15 \%$ and higher, it is an exemplary role for modern agricultural development in Hubei Province.

\section{B. To Major Projects as the Basis, to Increase the Efficiency of Agriculture}

Considering that the Hubei provincial Party committee and the provincial government made great efforts to promote the comprehensive reform in Wuhan Urban Agglomeration with the strategic plan. The Hubei provincial agricultural department actively organizes the implementation of soil testing formula fertilization, rural biogas, rural clean project and other major projects, which is effectively promoting the "two" agricultural construction. 
2012, the promotion of Wuhan Urban Agglomeration measured soil testing area of 3105 hectares, in addition, the per acre yield 27 kilograms, and acre of flat income more than 25 Yuan. All the success were achieved by the implementation of rural energy construction projects. What is more, the construction of household with biogas digesters 22 million, and with saving 2500000 tons of chemical fertilizer; 70 rural clean model villages construction and demonstration village of straw, feces, garbage, sewage and other organic waste processing utilization rate can reach more than $85 \%$.

\section{The Agricultural Service System as the Carrier, the Promotion of a Number of "Two Type" Agricultural Technology}

Relying on the agricultural science and technology service system in Hubei Province, the Agriculture
Department of province has promoted a number of advanced and applicable agricultural technologies, such as mulching 、 using fertilizer to adjust water, controlling nitrogen and increasing potassium, and releasing beneficial mite to control pest mite、 light trapping s straw biogas pyrolysis gasification and so on. Naturally, they will be more beneficial to reduce the delivery of fertilizers 、 seeds 、 pesticides v veterinary drugs 、 feed and feed additives. Beyond this, the latest datum of output of the main agricultural products in Wuhan Urban Agglomeration show (Table I.): the new technologies of Planting and Breeding industry have made important contributions to sustained increase of agricultural production and stable income of farmers in Wuhan Urban Agglomeration.

TABLE I. OutPut of The MAin Agricultural Products IN WUhan URban AGglomeration

\begin{tabular}{|c|c|c|c|c|c|c|c|c|c|c|c|}
\hline $\begin{array}{l}\text { Agricultural } \\
\text { Products }\end{array}$ & Year & $\begin{array}{l}\text { Wuhan Urban } \\
\text { Agglomeration }\end{array}$ & $\begin{array}{l}\text { Wu } \\
\text { han }\end{array}$ & $\begin{array}{c}\text { Huang } \\
\text { shi }\end{array}$ & $\begin{array}{c}\mathbf{E} \\
\text { zhou }\end{array}$ & $\begin{array}{c}\text { Xiao } \\
\text { gan }\end{array}$ & $\begin{array}{c}\text { Huang } \\
\text { gang }\end{array}$ & $\begin{array}{c}\text { Xian } \\
\text { ning }\end{array}$ & $\underset{\text { Tao }}{\text { Xian }}$ & $\begin{array}{l}\text { Qian } \\
\text { jiang }\end{array}$ & $\begin{array}{l}\text { Tian } \\
\text { men }\end{array}$ \\
\hline \multirow{3}{*}{$\begin{array}{l}\text { Output of Grain } \\
(10,000 \text { tons })\end{array}$} & 2014 & 1098.16 & 127.13 & 64.98 & 36.39 & 227.41 & 325.75 & 107.22 & 82.58 & 73.42 & 53.27 \\
\hline & 2013 & 1078.60 & 126.87 & 64.42 & 35.51 & 223.64 & 318.98 & 104.67 & 80.99 & 52.00 & 71.50 \\
\hline & 2012 & 1056.21 & 125.89 & 63.05 & 34.49 & 219.85 & 312.49 & 103.08 & 77.88 & 69.41 & 50.04 \\
\hline \multirow{3}{*}{$\begin{array}{l}\text { Output of Cotton } \\
\text { (tons) }\end{array}$} & 2014 & 19.00 & 2.05 & 0.55 & 0.48 & 3.13 & 5.00 & 0.36 & 2.29 & 3.05 & 2.09 \\
\hline & 2013 & 29.90 & 3.32 & 0.76 & 0.70 & 4.14 & 8.62 & 0.55 & 2.93 & 3.97 & 4.93 \\
\hline & 2012 & 30.96 & 2.46 & 0.73 & 0.74 & 4.46 & 9.33 & 0.52 & 3.10 & 5.33 & 4.30 \\
\hline \multirow{3}{*}{$\begin{array}{c}\text { Output of } \\
\text { Oil-bearing Crops } \\
(10,000 \text { tons })\end{array}$} & 2014 & 160.30 & 18.55 & 9.46 & 6.16 & 23.93 & 55.61 & 10.45 & 13.46 & 11.74 & 10.96 \\
\hline & 2013 & 159.85 & 18.66 & 9.38 & 6.09 & 24.21 & 55.39 & 10.19 & 13.05 & 11.42 & 11.46 \\
\hline & 2012 & 150.98 & 18.02 & 8.50 & 5.96 & 22.36 & 52.68 & 9.48 & 12.15 & 11.12 & 10.72 \\
\hline
\end{tabular}

Statistical yearbook of Hubei Province (2013-2015)

\section{To Reform as a Breakthrough, Explore New Ways of Land Scale Management}

In the past two years, in order to change the farmer farmland disperses, flower arranging, and the small size of the situation. With the purpose of promoting the centralization of land to farming experts, and industrialization of agriculture, Hubei Province Department of Agriculture focus on the innovative rural land circulation mechanism, which is foundation of the "government to cultivate the market, and the guideline to transfer the market. The circulation and promotion of the development maintains civil rights" of the land transformation mode, established village land circulation service station and the village land cooperatives. What is more, villages and towns established rural land trading center, and county also (city, district) set land transformation information sites, land contraction disputation and arbitration mechanism of land circulation service network. Through the transformation, which improves the land management efficiency, and increases the income of farmers. According to the survey, the circulation income per acre per year from the original 30-120 Yuan rose to more than 400 Yuan. By 2013, the Wuhan rural comprehensive property exchange 1470 transactions, the transaction amount of 8.92 billion Yuan, through the land contract management right mortgage, the total investment of 9 Yuan, accounting for more than $40 \%$ of the national rural land mortgage financing, revitalizing the land assets, and developing the rural economic injected vitality.

\section{PRomoting MEASURES}

\section{A. Enhance the Understanding, Strengthen the Organization and Leadership}

Hubei Provincial Department of Agriculture promoting the integration of agricultural industry in Wuhan Urban Agglomeration as their glorious responsibilities. In order to strengthen the integration of agricultural industry in the circle of the leadership, the Hubei Provincial Department of Agriculture established two types of agricultural work leading group which are responsible for the comprehensive coordination of Wuhan Urban Agglomeration "two" agricultural construction. Under the leading group office, anchored office Jicai department, who is in charge of the organization of agricultural industrial integration in Wuhan Urban Agglomeration implementation scheme and other daily work. Since the establishment of the project, leading group and officers participate in the Hubei provincial organization of the 1-2 conference, research, and project docking activities basically every month, in order to promote the Wuhan Urban Agglomeration "two" agricultural construction to do a lot of work. Wang Xiao dong who is the executive vice governor, and other provincial leaders all make highly accomplishment about this research. In order to deepen the agricultural strategy cooperation, Hubei provincial agricultural department has 
approved the establishment of the Wuhan Municipal Bureau of agriculture as a leader, Wuhan Urban Agglomeration within the eight Municipal Agricultural Bureaus of Wuhan Urban Agglomeration and "two type" agricultural joint work conference system, aimed at promoting the mutual exchange visits, resource surveys, information sharing, scientific and technological training, product marketing, agricultural super docking and other aspects of comprehensive cooperation, and to promote resource-saving and environment-friendly agricultural construction.

\section{B. Thorough Investigation and Research, Formulate Development Plan}

In order to work in Wuhan Urban Agglomeration agricultural industry, Hubei provincial agricultural department in accordance with the "Provincial government of Wuhan Urban Agglomeration "two type" social construction comprehensively reform pilot program", and make efforts to write the "Wuhan Urban Agglomeration agricultural industry integration implementation plan", the movement was praise by the executive vice governor Wang Xiao dong, and he also confirmed that Hubei province need to promote the comprehensive reform pilot Wuhan Urban Agglomeration, which is needed to be conducted by Hubei Provincial Agricultural Department issued within the city. The Planning set the clear development goals for Wuhan Urban Agglomeration agricultural industry integration, development layout, and development priorities. The planning also supports projects and related policies and measures promotion of integration of agricultural industry in Wuhan Urban Agglomeration, providing a guide for operation. At the same time, the Hubei Provincial Department of Agriculture also cooperated with the provincial development and Reform Commission, the provincial environmental protection department, and the Provincial Department of land and resources, in order to make the establishment of the Wuhan Urban Agglomeration two type of agricultural development planning, space layout planning, and environmental protection planning for the comprehensive construction of Wuhan Urban Agglomeration and the construction of "two type" society will provide policy support.

\section{Strengthen Platform Construction, Promote Information Service}

March 16, 2012, Hubei officially launched the Hubei 12316 rural comprehensive information service hotline, the full deployment of the 12316, the information is beneficial to farmers' activities. At present, Hubei Province farmers receiving nearly 1000 daily hotline, which built a good relationship between the government and the farmers by "Hot Line". Wuhan Municipal Agricultural Bureau to carry out 12316 theme activities, the with the joint many media in the city, and also to carry out on-site service, the day received more than 12316 hotline 500, 1 copies of promotional materials, 1000 farmers' questionnaire; 12316 Wuhan three agricultural hotline has been released, with 1991 fans, and 4367 people followed. According to the principle of classification, the province set up by 20 provincial experts, 100 counties and cities experts, 1000 experts from the township, a group of information services, free of charge for 12316 platform users to answer questions, and provide policy advice and related information services.

\section{Strengthen Exchanges and Cooperation, and Promote the Creation of Brand}

In order to enliven the Wuhan Urban Agglomeration agricultural product circulation, to improve visibility and market competitiveness of agricultural products, and to meet the urban and rural masses consumer demand, circle in agriculture, animal husbandry and fishery departments timely, which is based on the seasonal production of the agricultural products and market demand, to organize agricultural super docking and create the brand, it will circulate the agricultural products which referred to the province, not only in China, but also around the world. Effectively promoted the development of Wuhan Urban Agglomeration agricultural production. Around the theme of "Drinking Yangtze River Water, eating food of Hubei Province, tasting Jing Chu products", the tenth agricultural fair in organization in Hubei Province, more than 120 varieties of agricultural products and achieved the good results of 28 products gold prize and the best organization award, design award. Support Wuhan successfully hosted the ninth sessions of the Agricultural Expo, the participating enterprises to achieve sales of 2.5 billion Yuan; omre than 17000 kinds of agricultural products exhibitors, and more than 130 manufacturers, institutions, hotels to participate in marketing activities. What is more, more than 300 agricultural enterprises, farmers' cooperatives reached nearly 1 billion Yuan and 3 billion Yuan purchase intention. Activities in organizing the "Hubei famous brand" declaration, the 2012 organizations and 92 enterprises products to declare "Hubei famous brand", which will strive for the provincial leading enterprises, "three one" certification, agricultural products quality and safety indicators into the assessment of the conditions, enhanced the agricultural sector in the "Hubei famous brand" Review of discourse right.

\section{MAIN PROBLEM}

\section{A. Leading Enterprise Scale is Not Large, the Interests of Agricultural Enterprises is Not Tight.}

Hubei Province, above scale enterprises and all kinds of economic cooperated organizations with the overall strength, its power is not strong. Including the uneven development of the industry, such as the development of processing enterprises in the industry is relatively fast, but the development of livestock and poultry processing enterprises is relatively insufficient, especially the pig, chicken processing and the province of the province of pig and poultry is extremely disproportionate[5]. At the same time, the relative excess oil, crayfish and other industrial processing capacity, idle assets of many enterprises; the utilization rate is not high. Between leading enterprise and peasant household widespread interest, the connection is not tight, in addition, its order fulfillment rate is low. Thus, farmers for breach of contract and pacesetting enterprises with civilian dispute benefit both problems, is not conducive to industrial management of agriculture in our province. 
B. The transformation of scientific and technological achievements utility ratio is not high,the ability to make stable yield, high yield is not enough, and the efficiency for agriculture support capability is low.

Due to the imperfection of the running mechanism of basic-level agro-technique extension system, the utility ratio of agricultural sci-tech achievements in Hubei province is relatively low, the rate of application of the scientific and technological achievements is also low, the field rate of agricultural practical technology innovation achievements is not high either,. Beyond these disadvantages, the development of modern agricultural science and technology support ability is low, which restrict the development of Wuhan Urban Agglomeration of the agricultural industry integration developing agriculture and stable yield, high yield and efficiency enhanced security.

\section{Agricultural Products Market Volatility, the Pressure of the Continuous Increase of Farmers' Income}

Agricultural product market regulations and control mechanism are not perfect. Considering that the signal of price reflecting the supply and demand is not sensitive, the lack of necessary market risk warning mechanism to ensure that farmers make enough preparation to overcome difficult to adjust the structure of agricultural products, agricultural production is relatively in low efficiency, agricultural disasters caused by varying degrees of efficiency losses, the impact of farmers continued to increasing [6].

\section{Unbalanced Development of Industry and Regional Development}

Unbalanced industry development performance is an obvious problem in the past two years. In addition, several problems such as the industry investment, new projects rapid expansion of production capacity, low investment growth beyond the raw materials and market demand, all these problems have constrained industry development. Moreover, the regional development imbalance between high level of industrialization and investment incentives, and there is a large number of investment incentives which continues to expanding the industrial land, and gradually become the focus of agricultural products [7]. The imbalance between regions gradually evolved for the processing material, and production of raw materials gradually separated. Thus raw material of main origin of farmers are difficult to share the processing of agricultural products with high growth benefits, regional disparity expands unceasingly [8].

\section{COUNTERMEASURES AND SUGGESTIONS}

\section{A. Expanding Policy of Wuhan Urban Agglomeration "Three Rural" Insurance Coverage}

According to the national agricultural insurance policy, the central government has policy of agricultural insurance premium subsidies, planting industry has insurance more than $40 \%$, and aquaculture industry has insurance more than $50 \%$, in addition, the wider range of more underwriting fees, the more central financial subsidies. At present, Hunan province, Anhui province and other provinces have to give subsidies to all of the three rural insurance based on the policies While the Wuhan Urban Agglomeration only to sow, dairy cattle and rice and other three basic to ensure the protection, and has carried out the pilot of cotton, oil and vegetable insurance are only 1 counties (Tianmen) and 2 counties (Qianjiang, Wuxue). With the extension to further expand coverage, here is a suggestion that the expansion of cotton, rape and other agricultural insurance coverage. So cotton, rape and other types of insurance to ensure that the protection of agricultural production, and enhance the ability to resist risks.

\section{B. The Establishment of Special Funds to Support the Integration of Agricultural Industry in Wuhan Urban Agglomeration.}

In the process of financial support to the development of farmer professional cooperatives, the need to improve the accuracy of the target by reasonable selection of projects and other means to maximize the efficiency of the usage of fiscal funds [9]. In fact, the financial support for the development of agricultural industrialization is not an exception. So the implementation of Wuhan Urban Agglomeration of the agricultural industry integration, involving sectors, wide range, which requires a lot of human, material and financial resources. Here is a suggestion to the government to lists the special funds to support the Wuhan city, Hubei province need to implement agricultural integration, or building an existing in Wuhan Urban Agglomeration of special funds to clear "a piece of" supporting the construction of agricultural industrialization.

\section{To Enhance Investment in Wuhan Urban Agglomeration Agricultural Funds Supporting}

Nearly three years, in Hubei province agriculture department for the Wuhan Urban Agglomeration for agricultural capital construction projects capital of 1.425 billion Yuan, but given that the local financial resources is limited, most of the projects did not form a complete set, or lack of form a complete set. For example, agricultural products quality inspection system, planting the seed project, agricultural pest warning and control area station project, standardization of pig farming village project, and aquatic animal epidemic prevention station project. If all the projects get supported it would need 280 million, but is less than $10 \%$ of form a complete set. These problems influence content completion project construction and project completion acceptance, impact on the central project, suggested that local governments at all levels of government of Hubei province and Wuhan Urban Agglomeration to enhance investment in matching funds for project, in order to win more and more large projects in the national wide.

\section{To Further Increase the Intensity of Investment Promotion and Capital Introduction}

Investment promotion and capital introduction are two important methods to promote the Wuhan Urban Agglomeration agricultural product processing industry structure adjustment and to improve industrial upgrading. Yinlu group put these modes into production, the tax one hundred million Yuan is a model of success to increase the intensity of investment promotion and capital introduction in various cities, with key demonstration garden, the key 
leading enterprises, and major industry support projects as a platform, it is effective to encourage enterprise companies which has business investment, and strong project, so that ensure that foreign capital can retain easily with benefits. Through the investment promotion and capital introduction, and further improvement of the intensive degree of advantage industry of Anhui province will be achieved. Moreover, this strategy can achieve industrial upgrading as soon as possible. Support leading enterprises bot in and out of the province, encourage these companies to enter the national wide and world wide range by setting up a research center to develop transnational operation [10].

\section{ACKNOWLEDGMENT}

The paper was supported by the National Science \& Technology Pillar Program during the Twelfth Five-year Plan Period (No.2013BAD20B) and Public Welfare Science and Technology Research Project of Hubei Province (No.2012DBA32001).

\section{REFERENCES}

[1] Hua jing and Wang Yubin, "An empirical study on the development of agricultural industrialization in China," Inquiry Into Economic Issues, vol. 4, Apr. 2015, pp. 70-74.

[2] Niu Ruofeng, "The agricultural industry integration management theoretical framework," China Rural Economy, vol. 5, May. 1997, pp. 4-8.

[3] Wang Yafei and Tang Shuang, "In the process of agricultural industrialization leading enterprises and farmers in our country's theory of game analysis and improvement-system characteristics of different organization model," Issues in Agricultural Economy, vol. 11, Nov. 2013, pp. 50-58.

[4] Han Yanqi, Zhang Yinling and Wang Hongling, "The existing problems and Countermeasures of agricultural industrialization management in Hubei province," Hubei Agricultural Sciences, vol. 53, May. 2014, pp. 713-718, doi: 10.3969/j.issn.0439-8114. 2014. 03.059.

[5] Xiao Anmin, “Annual Report on Development of Wuhan Urban Agglomeration (2010-2011) ," Beijing: Social Science Literature Press, 2011.

[6] Warning, M. and Key, N, "The Social Performance and Distributional Consequences of Contract Farming: An Equilibrium Analysis of the Arachide de Bouche Program in Senegal," World Development, vol. 30, Feb. 2002.

[7] Zhang Shiru, "Research on the development of strategic emerging industries and the problems of agricultural industrialization," Issues Agricultural Economic, vol. 2, Feb. 2012, pp. 79-84.

[8] Mo Huiying, Hu Kai and Liu Chaoyong, "Research on the Influence Mechanism of Industry Characteristics and Innovation Policy on R\&D Intensity-Empirical Analysis Based on Agriculture Leading Enterprise in jiangxi Province," Technolocy and Innovation Management, vol. 35, Sep. 2014, pp. 446-450, doi: 10.3969/j.issn.1672-7312.2014.05.009.

[9] Xiao qin, Li jinping, Li junjie, Ji Yue, Niu Yunxia and Chi Liang, "Study on the Targeting Mechanism of Financial Support for Farmer Cooperatives: Thinking Based on the Management Project of Comprehensive Agricultural Industry Development in a City at the Eastern China," Issues Agricultural Economic, vol. 8, Aug. 2015, pp. 98-104

[10] Zhang Min, Lu Xianghu and Qin Fu, "Learn from experience of developed countries to Promote agricultural industrialization rapid development of china," Issues Agricultural Economic, vol. 4, Apr. 2011, pp. 4-9 